\title{
EL ARGELINO ALBERT CAMUS
}

\author{
MANUEL GÓMEZ
}

\begin{abstract}
Conferencia pronunciada el día 15 de marzo de 2017 en el Salón de Grados de la Facultad de Filosofía y Letras de la Universidad de Alicante, y traducida del francés por Naima Benaicha Ziani.
\end{abstract}

Nací en Elche en una familia tradicional formada por los GómezBrufal-Valdivia. Mi abuelo Manuel Gómez Valdivia fue presidente del Partido Democrático, de la Diputación Provincial desde el año 1916 al 1920, y Gobernador Civil de la Provincia de Castellón de la Plana. En cuanto a mi padre, José Gómez Brufal, fue abogado y también político, llegó a ser asesor de los Reyes de Marruecos, Mohamed V y Hassan II.

Cuando apenas contaba con quince años conocí a Albert Camus, que trabajaba en ese momento en el periódico Alger Républicain, con sede en la ciudad de Argel. Ese primer encuentro fue breve, pero determinante, porque me animó a emprender mi carrera en el periodismo. A finales de 1954, y por motivos ideológicos, tuve que dejar el periódico para empezar en otro rotativo, La Dépêche d'Algérie. Finalmente acabaría siendo corresponsal del periódico parisino l'Aurore. En 1958 comencé a trabajar en la sección de investigación del mismo periódico, y es allí donde volví a encontrarme con Camus. A partir de allí nuestros encuentros fueron más frecuentes. Desayunábamos en la Brasserie Lipp donde me confiaba sus artículos para después publicarlos en el periódico l'Aurore. Les hablaré de Albert Camus, nacido de padre "Sol" y de madre "Mediterráneo", hijo de Argelia. Sin ninguna duda, Camus es uno de los referentes más importantes de la Argelia moderna. Y no estamos hablando, precisamente, de Camus el escritor.

Albert Camus y Sintes nació el 7 de noviembre de 1913 en Mondovi, un pueblo cercano a Bône (actual Annaba), puerto principal para los emigrantes que llegaban de Francia, mientras que los españoles que procedían de Alicante y Murcia pasaban generalmente 
por el puerto de Orán. Con un año de edad, su madre se vio obligada a trasladarse a Argel donde Camus realiza sus estudios. Su padre ya había fallecido en 1914, nada más empezar la Primera Guerra Mundial. Gracias a su maestro en el colegio - quien descubrió su genio - pudo obtener una beca que le permitiría realizar estudios superiores. Como bien sabemos, Camus pertenecía a una familia muy humilde. Para ir al colegio a menudo hacía un tramo a pie para ahorra dinero. Albert era muy deportista, un hecho que le empujó a escribir: "Es en el deporte y en el nudismo donde no se ven las desigualdades".

Sin embargo y a pesar de su condición social, consiguió inscribirse en el club más prestigioso de Argelia: el RUA, Racing Universitaire Algérois. Era una forma de salir del entorno y el barrio en los que vivía. No quería ser como los jóvenes de su barrio. Quería destacar, y lo consigue cuando ingresa en la universidad. Más tarde se integra en un equipo de fútbol donde juega como guardameta. Su falta de técnica como jugador en el campo y su frágil salud sólo le daban para ser portero. Este puesto le venía como anillo al dedo, le convenía porque le gustaba ser el último en la defensa. Ya de joven le gustaba que se contara con él como pieza importante. Sólo que, poco después, una mala noticia le cae como jarro de agua fría: le diagnostican tuberculosis. A su pesar se ve obligado a abandonar el fútbol y todo lo que tenía que ver con el esfuerzo físico.

En 1930 es internado en el hospital Mustafa, un hospital considerado como "hospital de los barrios pobres", y es allí donde toma consciencia de su condición social, y de lo mucho que debe esforzarse para sacarle partido a su inteligencia, si es que quería salir de la pobreza. Y no hay mal que por bien no venga, Camus reconoce que si no fuera por su estado de salud - que le impidió hacer carrera como futbolista- probablemente jamás se habría convertido en el intelectual que más tarde será conocido a nivel mundial. Argelia habría ganado un gran guardameta, pero habría perdido un gran Premio Nobel. Llegó a escribir: "Mi único objetivo es y será vencer la muerte, una horrible y sórdida enemiga".

Su mentor y profesor de filosofía, Jean Grenier, le anima y le apoya en su trayectoria de escritor, hasta que se marchó de Argelia. 1930 es una fecha importante, el centenario de la conquista francesa de 
Argelia, fecha que le marca para siempre. Empieza a pensar de forma distinta, de sentir miedo hacia el futuro de Argelia. Hasta esa fecha sólo se preocupaba por el deporte y sus estudios. La política no ocupaba sitio importante en su vida. Su enfermedad le obligó a precipitar los acontecimientos y tomar consciencia de su inferioridad social. Sabía que no tenía los mismos privilegios que otros, y había que conquistarlos, costara lo que costara. Decide, pues, salir de la pobreza que le había tocado vivir desde su nacimiento, y se integra en el RUA. Con frecuencia se dejaba ver en la piscina de este club, codeándose con la élite intelectual de la capital argelina. Apenas tenía 17 años.

Sus nuevos amigos, liderados por Max-Pol Fouchet y pertenecientes a la élite, no lo tomaban en serio. A menudo afirmaba que entre el fútbol y el teatro, se inclinaba más hacia el primero porque se sentía más cómodo en un terreno que un escenario. En estos momentos Camus estaba locamente enamorado de la amante de Max-Pol Fouchet, Simone Hié. Este mismo año de 1930 se produce el asesinato de un "árabe", argelino, lo que marca un antes y un después en la vida cotidiana de todos los habitantes de Argel. Este hecho le lleva a escribir la novela El extranjero. En un reencuentro con Camus en París en 1958, me confirmó el hecho. Según contaba, escribió la novela $\mathrm{El}$ extranjero incitado por el estilo literario de François Sierra. Después de leer sus escritos, Camus pensó que iba siendo hora de dar a conocer y que los demás comprendieran la importancia del honor, el profundo sentido de la promesa, tan desarrollado y fuerte entre los mediterráneos. En la página 280 de la publicación póstuma de su novela Le Premier Homme, "El primer hombre", confirma dicho honor.

Después de aprobar el baccalauréat, Camus elige un nuevo punto de encuentro: La Brasserie de la Renaissance, cerca de la universidad, calle Michetea, en Argel. Entonces decide buscar un estilo dintinguido de vestimenta, y empieza a vestir con un traje gris claro, camisa y calcetines blancos y calzado bicolor, siempre reluciente, y un sombrero borsalino. De alguna u otra forma, había que destacar. MaxPol Fouchet, el incontestado líder de la élite intelectual en Argel en aquel entonces, no ve con buenos ojos competir con Camus. Decía que no podía haber dos rois en el mismo círculo, un círculo de la 
izquierda burguesa. Sólo había una forma de poder avanzar para Albert, cortejando a Simone y, pocos años más tarde, casándose con ella. Ante semejante desafío, Max-Pol abandona Argel y se instala a París. Poco tiempo después, la espléndida Simone pierde su encanto y cae en una profunda crisis por causa del excesivo consumo de drogas.

En 1937 Camus intenta acceder a un puesto de trabajo en la universidad, pero la tuberculosis no le permite cumplir su deseo. También, y por culpa de dicha enfermedad, se queda con las ganas de alistarse para defender España junto a los republicanos. Aquella fue la mayor de sus frustraciones. La mayoría de los expatriados españoles en Argelia eran "rojos" y muchos de ellos lucharon con las Brigadas Internacionales. Esto explica su profundo compromiso y fidelidad con la causa republicana española. Recordemos que los abuelos maternos eran de la isla de Menorca, y sangre española corría por sus venas también. Varias son las obras que justifican su amor por España: Révolte dans les Asturies, L'État de siège, La dévotion à la croix (adaptación de Calderón de la Barca), Le chevalier d'Olmedo (haciendo referencia a Lope de Vega), donde escribía: "Amigos españoles, en parte, compartimos sangre, y lo que siento hacia vuestra patria es la literatura, vuestro pueblo, vuestra tradición, una deuda que no se saldará nunca”.

En 1938 Camus entra a trabajar en el periódico de tendencia comunista Alger Républicain, que pronto dirigirá. En ese momento conoce a Ferhat Abbas, líder de los revolucionarios argelinos. Por aquel entonces Ferhat, al igual que Camus, abogaba por una Argelia unida y reivindicaba más derechos para los árabes. Quería que tuvieran el derecho de acceder a la nacionalidad francesa y convertirse en ciudadanos de verdad.

Camus decide cambiar Argel por Orán en 1939. Allí conoce a una bella oranesa, Francine Faure, que tuvo el mérito de encauzar a este Don Juan, amante de las mujeres. Tuvieron dos hijos. Un año más tarde se mudan a Francia donde Camus se reencuentra con su amigo Robert Namia. Trasladan el periódico Paris Soir a Lyon huyendo de la ocupación Nazi. Poco tiempo después regresan a Orán para volver a dejarla en 1942 con dirección, de nuevo, a París, para luchar contra los alemanes. No podía permanecer pasivo ante la guerra de entonces. 
Hasta el final de las hostilidades se hizo miembro del grupo de resistencia Combat, convirtiéndose en un miembro muy activo.

Una vez finalizada la guerra se suma a la corriente izquierdista y sigue con su carrera literaria y filosófica, con Sartre de padrino. Sin embargo los atentados de mayo 1945 le obligan a seguir sumergido en la Guerra de Argelia, siendo consciente que Ferhat Abbas era ya uno de los incitadores. Días después Maurice Thorez, líder del Partido Comunista francés y vicepresidente del consejo, escribe en l'Humanité provocando la ira de Camus: "Los instrumentos criminales son los líderes del PPA, como Messali Hadj y los chivatos camuflados en las organizaciones que pretenden ser nacionalistas y que cuando Francia estaba bajo el dominio fascista, ni han dicho nada ni tampoco han hecho nada. Y ahora reclaman la independencia. Hay que castigar rápida e impiadosamente a los que incitaron a la discordia con armas".

Se aleja de forma muy aparente del comunismo, y junto a numerosos intelectuales, firma la solicitud de gracia a favor del escritor Robert Brasillach, condenado a muerte por sus escritos antisemitas, y que días más tarde fue ejecutado. Su obra L'homme révolté es mayor prueba de ello. Es una obra que denuncia el estalinismo y su cómplice, el PCF. Un mes antes de la declaración de la guerra el 1 de noviembre 1954, Ferhat Abbas escribe a Camus: "La ira está en su apogeo. Argelia no está tranquila y el divorcio se puede producir en cualquier momento". Desde entonces Camus se implica de pleno en los asuntos de la guerra de Argelia, pero a nivel político sufre el estigma de ciertos hombres, incluso de los más allegados. Cincuenta y siete años después me parece que es necesario restaurar ciertas verdades deformadas respecto a Camus.

Ante todo me he propuesto demostrar a los franceses de Argelia que sus razones tendrán para pensar que Camus les traicionó, que Camus era partidario "moderado pero entregado" de la independencia de Argelia. Esa impresión estaba fortalecida por sus ideas políticas, siempre posicionadas a la izquierda, pero sobre todo por la trampa que les tendieron los "amigos" izquierdistas al invitarle a participar en una conferencia a la que yo mismo asistí. El domingo 22 de junio de 1956, efectivamente, le invitaron a una conferencia que tuvo lugar en el Cercle du Progrès, Plaza del Gobierno, en la Casba. Se trataba de una 
provocación organizada por los partidarios de la independencia y los liberales de Argel. Era una oportunidad para demostrar a todos los que seguían la causa desde fuera que Camus les apoyaba en su lucha. Estando fuera de Argel, Camus no podía suponer ni un instante que los organizadores eran miembros del FLN.

Esa misma noche Camus perdió toda credibilidad a los ojos de los franceses de Argelia. Me lo encontré esa misma noche y le recordé que gracias a su intervención, empecé mi trabajo como periodista en el Alger Républicain. Estaba completamente desesperado: "Soy sospechoso para los nacionalistas de ambos lados. Para algunos, estoy equivocado, no soy lo suficientemente patriótico y para otros tampoco lo soy. Lo que muchos árabes no entienden es que amo a Argelia como un francés que quiere sentirse en casa, en Argelia, sin que tenga que sentirme extranjero".

Desde esa fecha mi principal objetivo ha sido, pues, el de rectificar esa impresión que tanto unos como otros tenían de Camus. La quiero borrar y quiero recordar lo que en Combat llegó a escribir: "Argelia es una extensión de Francia, sin ella nuestro país no sería una gran nación". De esta forma defiendo y quiero que Camus vuelva a ocupar el lugar que le corresponde en el corazón de los algérois. En 1955 escribe en el magazine L'Express:

Entre la metrópoli y los franceses de Argelia, nunca estuvo más grande la brecha. Al leer cierta prensa, da la sensación que Argelia esté poblada por un millón de colonos con un látigo, un puro y circulando en Cadillac. El 90\% de los franceses de Argelia no son colonos, sino más bien asalariados, artesanos o comerciantes. Su nivel de vida es mucho inferior al de los de la metrópoli. Aqui van dos ejemplos: el salario mínimo es claramente inferior al de los que viven en las zonas más desfavorecidas de la metrópoli. En cuanto a las ayudas sociales, un padre de tres hijos percibe aproximadamente 7.200 francos frente a los 19.000 que reciben en Francia. ¿Quiénes son los que se aprovechan de la colonización aqui?

Los apoyados en la cómoda indiferencia de la prensa y de la opinión pública, los gobiernos sucesores, son los primeros y verdaderos responsables del desastre actual. En cualquier caso, son mucho más culpables que los cientos de miles de trabajadores franceses que sobreviven en Argelia con sueldos de miseria y que cada dos por tres salen, armados, en defensa de la metrópoli. Hoy se ven recompensados con el desprecio de los que han salvado. 
Se distancia de los militantes de la izquierda cuando se da cuenta que sus "amigos intelectuales" colaboran con los enemigos de la Argelia francesa, especialmente desde dentro de la red Francis Jeanson "les porteurs de valises (los portadores de maletas)" que financian a los terroristas. Dimite porque no comulga con ellos.

Tuve el privilegio de encontrarme con Albert Camus más de una vez durante los años 1958 y 59. En julio de 1958, algunas semanas después de mi llegada a París, nos tomamos algo en la Brasserie Lipp, que Camus frecuentaba mucho. Me confesó haber salido totalmente agitado de una entrevista que había tenido con Charles de Gaulle algunas semanas antes, el 5 de marzo. Me contaba (Chroniques algériennes, juin 1958, Gallimard):

Al hablarle de los riesgos que correríamos si Argelia se perdiese, e incluso de la ira de los franceses de Argelia, le pedi que me confirmase de nuevo su voluntad de no ceder y seguir conservando la Argelia para Francia. Me asombré de que sus palabras dejaban lugar a dudas. De Gaulle me contesta: "Como hombre politico, nunca creas lo que te diga, uno se puede llegar a asombrar cuando cree en las palabras".

Esa misma tarde Albert Camus me habló largo y tendido sobre el 13 de mayo de 1958, del enorme cambio que se había producido en las mentes en Argelia. Me explicó que esos cambios le habían producido mucha esperanza, a la vez que miedo, porque venía de reunirse con André Passeron, periodista en el diario Le Monde, nacido en Argel. Le había confirmado la intención de De Gaulle de darle la independencia a Argelia antes de 1958. Palabras textuales de De Gaulle:

Le di muchas vueltas al caso de Argelia, desde siempre y antes de volver al poder, $e$ incluso una vez en el poder. Después de haber estudiado el problema, supe y decidí que habria de darle a Argelia su independencia. Pero imaginese que cuando fui a Argel, si hubiera dicho públicamente que los argelinos debian de tomar ellos mismos su gobierno, entonces De Gaulle habría desaparecido, me habrian eliminado al instante. Por eso mismo tenía que tomar precauciones, pero esta misma idea la tenía desde el principio.

Me afirmó que algunos familiares intentaron hacerle ver que lo que había sucedido en Argelia no era para nada espontáneo. ¡Que entre franceses y árabes no había nada de fraternidad ese día! Que el 
ejército francés lo había organizado todo en las aldeas y los pueblos enviando varios camiones. Camus me preguntó entonces: “' Tú que has tenido la suerte de vivir estos acontecimientos el 13 de mayo, que me dices? ¿Cómo los viviste?". Le confirmé que en las ciudades, el impulso fue espontáneo, pero que no podía decir nada de los pueblos, puesto que no estuve allí. Sin embargo, me pareció lógico que el ejército francés pusiera camiones al servicio de los árabes que querían desplazarse hasta la capital para manifestarse. Cómo lo iban a conseguir sin esta ayuda. En mi opinión, nadie les iba a embarcar a la fuerza sin provocar que la prensa internacional se enterase. "Quiero pensar - me dijoque asi fue”. De hecho había antecedentes, exactamente en 1930, durante el centenario de Argelia (1830-1930). El ejército francés ya había puesto sus camiones al servicio del pueblo.

En ese momento pude ver la duda en su mirada. Este hombre lo sentía, estaba muy afectado por los acontecimientos en Argelia y en Francia. No podía estar seguro de nada y con las lágrimas en los ojos, me dijo:

Nunca estaré de acuerdo con abandonar Argelia. Y es por varios motivos, siendo el principal que dejándola, en un decenio, Argelia volvería al estado inicial en el que la encontraron nuestro antepasados. ¿̇sería justo que después de más de un siglo de duro trabajo, de sudor y lágrimas, todo se iría al garete por este impulso histórico? No quedaría nada. No, debe de existir una solución y nos toca a nosotros, gente de buena voluntad, de encontrarla y aplicarla.

A principios del año 1959 fuimos juntos al teatro Gaumont en París, a ver La Famille Hernández, y después fuimos a cenar acompañados por Marthe Villalonga y Robert Castel, los dos protagonistas de esta obra folklórica. Me dijo Camus:

Ves, nos hemos reído mucho, pero los franceses de la metrópoli no deberian de ver, a través de estos espectáculos, la verdadera cara de los franceses de Argelia. Sería falso e imperdonable. Estas escenas pertenecen a nuestro folklor de la misma forma que lo son espectáculos como Mystères de Paris, ¡"Le Bal à Jo!, o bien Bourrée auvergnate, a los metropolitanos.

Es nuestro deber mostrar que los franceses de Argelia, hablan, ciertamente, con un acento, igual que cualquier francés de cualquier región de a metrópoli, excepto, parece ser, los de tourangeux, pero no les envidian nada en cuanto a sintaxis o pureza del lenguaje. Les toca a periodistas como tú recordarles, cada vez, esta verdad. Tenéis que nombrarles en cada ocasión nombres de franceses de nuestro país 
que pertenecen a la élite francesa: hombres de letras, profesores, abogados, cirujanos, médicos, deportistas de alto nivel, actores, cantantes, músicos y como no, políticos. Deberiamos de recordarles, sin escatimar, que Argelia dio a Francia sus mejores bijos sin negociarlo.

Me informó Camus que estaba trabajando en una novela. Decía:

Siempre he tenido la sensación de "parirla" sin que para ello tenga tiempo. Nunca tenemos tiempo para lo esencial, lo real, para lo único que cuenta. Perdemos mucho tiempo en lo superficial.

Siempre he tenido el sentimiento de no poder nunca acabar de escribir el único libro que he querido siempre escribir, sobre mis raices, mi familia, mi infancia. Sobre todo aquello que ha contribuido a forjar al hombre que hoy soy.

Se trataba, por supuesto, de la novela Premier homme, publicada mucho tiempo después de su muerte, en la que escribe dirigiéndose a los árabes: "Os defenderé a cualquier precio, pero no al de mi madre, porque ella, más que vosotros, ha conocido mucho dolor y sufrimiento. $Y$ si en un arrebato rabioso me la tocáis o lo intentáis, me convertiré en el peor de vuestros enemigos". Veneraba a su madre, una madre que se sacrificó por él a pesar de sus limitaciones. Era en parte sorda y analfabeta. Muy a menudo hacía referencia a su madre en sus declaraciones. Pocas veces nombraba a su padre, a quien conoció sólo a través de las fotos. Su padre, Lucien Auguste, nacido en 1885 en Ouled-Fayet, cerca de Argel, se casó con Catherine, la madre de Albert, el 23 de noviembre de 1909. Su padre, después de una grave herida en la cabeza que lo dejó ciego, murió en el frente, en un hospital fuera de la ciudad el 11 de octubre de 1914. Era, en fin, junto a su tío Gustave Acault, un albañil anarquista que se había criado y educado dentro de esta inclinación política.

El 10 de diciembre de 1957 recibe el premio Nobel y da un discurso vibrante en el que homenajea a Louis Germain. Después de una llamada de atención de un joven árabe sobre los acontecimientos en Argelia, Camus le contesta:

Siempre he condenado el terror. De igual manera, debo condenar cualquier terror que se ejerza ciegamente, en las calles de Argel, por ejemplo, y que le pueda tocar a mi madre o a mi familia. En el momento en el que estamos hablando, están tirando bombas en el tranvía de Argel. Mi madre podría estar en uno de esos trenes. jSi ésta es vuestra justicia, prefiero mi madre a vuestra justicia! 
Siete días más tarde confirma esta afirmación escribiendo en el periódico Le Monde, el 17 de diciembre.

Durante el mes de diciembre de 1959 me encuentro con Albert Camus en la Brasserie Lipp, en París, para comer con él y con Pierre Blanchar. Este último era un actor que había nació en Philippeville, en el mismo edificio que mis abuelos. Entonces se contaba entre los actores más famosos del cine francés, con más de ochenta películas. Le propuse a Camus invitarle al teniente coronel Ahmed Rafa, que dirigía el 7o Regimiento de los Tiradores argelinos. Se encontraba de paso por París, donde fue recibido por De Gaulle. Rafa insistía en informarnos sobre su entrevista con De Gaulle por haberle causado gran impresión. Enseguida congeniaron. De qué me sorprendo, sabiendo el amor que ambos, Camus y Rafa, profesaban por Argelia. ¿Quién mejor que Camus para comprender los sentimientos de Rafa? En 1961, Rafa es el primer General franco-argelino del ejército francés.

Ese día quedará grabado en mi memoria por dos razones. La primera es porque fue la última vez que me encontré con Camus. La segunda es que Albert se había dejado llevar, totalmente, por sus verdaderos sentimientos con respecto a la guerra de Argelia. Ese día vi cómo Camus había perdido el norte. Lo que le había contado Rafa no era para menos. Rafa nos había explicado que, respetuosamente, le había preguntado a De Gaulle por qué no tenía pensado integrar los tres departamentos franceses de Argelia dentro de Francia. La respuesta de De Gualle le dejó sin palabra:

Ya lo expliqué, pero se lo digo de nuevo: cada año nacen en Francia 800.000 niños y otros 600.000 en Argelia de matrimonios exclusivamente musulmanes. Le es imposible a Francia absorber un colectivo tan grande y tan heterogéneo sin que se vea afectada en su personalidad y su unidad. Es pues extremadamente peligroso pretender hacer de Argelia una provincia francesa.

Rafa nos afirmó que admiraba a De Gaulle por su valentía y por donde había colocado a Francia en el mundo. Se merecía gloria y respeto, pero ya no para él. Camus no entendía nada. No entendía esta violencia y este odio que se proferían los dos pueblos. Decía que lo tenían todo para entenderse. En el libro L'Homme et l'Amour decía lo 
siguiente: "Hay que parecerse un poco para entenderse, pero bay que ser un poco diferente para amarse. Si, parecidos y diferentes. ¿No es lo que somos?".

Camus sabía que eran las promesas no cumplidas por Francia las que habían llevado a esta discordia. Veíamos venir ya lo que De Gaulle había decidido para Argelia. Camus nos lo señala con firmeza:

Si el día de mañana el poder nos impone un referéndum sobre la independencia de Argelia, me pronunciaré en contra, sin equivoco, tanto en la prensa francesa como en la argelina. Mantengo que argelinos, franceses y musulmanes, deben convivir.

Disfrutaba repitiendo esta frase: "Argelia es católica el día de Todos los Santos, musulmana en l'Aid El-Kebir y judia en Yom Kippour". Aún me acuerdo de una de sus últimas confidencias:

\begin{abstract}
Siempre he abogado por la igualdad entre todos los hijos de Argelia, sin preponderancia de una comunidad sobre otra. Es una de las razones por las cuales siempre me he pronunciado en contra del colegio único. Lo dije, lo escribi, y hoy lo vuelvo a afirmar más alto todavia: la independencia de Argelia es una herejia. Otras soluciones son posibles, incluso deseables.
\end{abstract}

Días más tarde Camus se fue a celebrar la Navidad con su familia en Lourmarin en el Lubéron. Quedamos en vernos a su regreso y acordamos encontrarnos donde siempre, en el Lipp, hacia mediados de enero. Tenía que disfrutar de su estancia en el pueblo para "dar a luz" un artículo en el que iba a criticar la política gaulista, que me entregaría a su vuelta y que publicaría en el periódico L'Auror. Se había instalado en Lourmarin, en la misma región de donde provenía su bisabuelo que un siglo antes había partido para Argelia. Vivía allí con su familia y un "borrico" que Pierre Blanchar le había enviado desde Philippeville.

Pero nada de esto se hizo porque Albert Camus fallecía el 4 de enero de 1960 en un accidente de tráfico, en la nacional 6, mientras se dirigía a París en un coche que conducía Michel Gallimard, el hijo de su editor. Durante varias semanas el taller de Lourmarin, que llevaba el mantenimiento del "Facel Vega" del hijo de Gallimard, le decía a éste que fuera pensando en cambiar los neumáticos del coche, ya desgastados. Si lo hubiera hecho quizás el accidente no habría tenido lugar. O bien, a pesar de las fuertes lluvias y las calzadas mojadas, quizá el accidente no hubiese sido mortal. 
Mucha gente se permite interpretar los pensamientos de Camus, algo que me niego a hacer a pesar de haberlo conocido mucho más de los que ni siquiera lo han abordado. Efectivamente, estaba enfadado con la izquierda... o quizás era la izquierda la que estaba enfadada con él. En cuanto a la derecha, el rechazo era mutuo. Me dijo: "Es el cometido de periodistas como tú de recordarles, sin descanso, la verdad". Y me confió esta última declaración, publicada en el periódico L'Aurore: "He amado con pasión la tierra que me vio nacer. De ella cogi todo lo que boy soy y nunca separé a mis amistades que en ella viven". Eso mismo intento hacer desde que desapareció.

Acabo este texto con esta cita de Albert Camus, escrita hace más de sesenta años y que sigue de actualidad: "El papel de nuestra generación no consiste en rehacer el mundo, sino evitar que se deshaga".

Hubo un tiempo en que Argelia fue francesa. En la primavera del 62, Albert Camus ya no estaba entre nosotros, pero yo sí. Estaba aquí, en Alicante, dando recibimiento a unos cuantos miles de franceses de origen español que habían elegido volver a la tierra de sus antepasados. En su nombre agradezco a la provincia de Alicante por el acogimiento que les brindaron. En homenaje a esta acogida, la Casa de Francia, la Maison France de Alicante, inauguró en la Explanada el año de 2014 un monumento en memoria de este acontecimiento. 